\title{
Novel strategy to monitor fluid absorption and blood loss during urological endoscopic surgery
}

\author{
Yunxin Zhang ${ }^{1,2,3}$, Ning Fan ${ }^{1,2,3}$, Lixiu Zhang ${ }^{2,3}$, Xuemei Hu ${ }^{2,3}$, Li Wang ${ }^{4}$, Hanzhang Wang ${ }^{5}$, \\ Dharam Kaushik ${ }^{5}$, Ronald Rodriguez ${ }^{5}$, Zhiping Wang ${ }^{1,2,3}$
}

${ }^{1}$ Department of Urology, The Second Hospital of Lanzhou University, Lanzhou, China; ${ }^{2}$ Institute of Urology, The Second Hospital of Lanzhou University, Lanzhou, Gansu, China; ${ }^{3}$ Key Laboratory of Urological Diseases in Gansu Province, Gansu Nephro-Urological Clinical Center, Lanzhou, China; ${ }^{4}$ Department of Pharmacology, School of Basic Medical Sciences, Lanzhou University, Lanzhou, China; ${ }^{5}$ Department of Urology, University of Texas Health Science Center, San Antonio, TX, USA

Contributions: (I) Conception and design: Z Wang, Y Zhang, D Kaushik, R Rodriguez; (II) Administration support: None; (III) Provision of study materials or patients: N Fan, L Zhang; (IV) Collection and assembly of data: Y Zhang, N Fan, L Zhang, X Hu; (V) Data analysis and interpretation: Y Zhang, L Wang, H Wang; (VI) Manuscript writing: All authors; (VII) Final approval of manuscript: All authors.

Correspondence to: Zhiping Wang. Department of Urology, The Second Hospital of Lanzhou University, \#82, Linxia Road, 730030, Lanzhou, China. Email: erywzp@1zu.edu.cn.

Background: There is paucity of an optimal method to detect fluid absorption and hemorrhage during urological endoscopic surgery. We designed an endoscopic surgical monitoring system (ESMS) and estimated its performance to establish a practical instrument that can monitor the blood loss and fluid absorption accurately and non-invasively during urological endoscopic surgery.

Methods: Our system employed the strain gauge transducers to detect the inflows and outflows of the irrigating solutions and the photoelectric sensor to determine the hemoglobin concentration of the collected irrigating fluid. The amount of blood lost and the volume of fluid absorbed during endoscopic surgery could be calculated by computer program. The accuracy and validity of this system were validated in simulated experiment and clinical study of 200 patients who underwent transurethral resection of the prostate (TURP). Results: The relative errors for fluid absorption detection were between $0.07 \%$ and $1.00 \%$ and the coefficient of variation in serial analysis ranged from $0.78 \%$ to $3.86 \%$. Furthermore, the relative errors for blood loss detection were between $0.06 \%$ and $1.33 \%$ and the coefficient of variation in serial analysis ranged from $0.86 \%$ to $3.94 \%$. In clinical study for TURP, the mean fluid absorption was $644 \mathrm{~mL}$ and blood loss was $238 \mathrm{~mL}$.

Conclusions: We provide the accuracy and validity of ESMS. It provides an early and real time detection and warning of irrigation fluid absorption and blood loss to make endoscopic surgical procedure safer for the patient.

Keywords: Blood loss; irrigating fluid absorption; photoelectric sensor; strain gauge transducer; transurethral resection of the prostate (TURP)

Submitted Nov 25, 2019. Accepted for publication May 13, 2020.

doi: $10.21037 /$ tau-19-780

View this article at: http://dx.doi.org/10.21037/tau-19-780

\section{Introduction}

Fluid absorption can occur when irrigating solutions are being used in endoscopic operations. However, the phenomenon is most frequently associated with the transurethral resection of the prostate (TURP), percutaneous nephrolithotomy (PCNL), and transurethral resection of bladder tumor (TURBT). Excessive absorption of irrigating solution may result in transurethral resection syndrome (TURS) which is life-threatening complication that consists of disturbance of the circulatory and central 


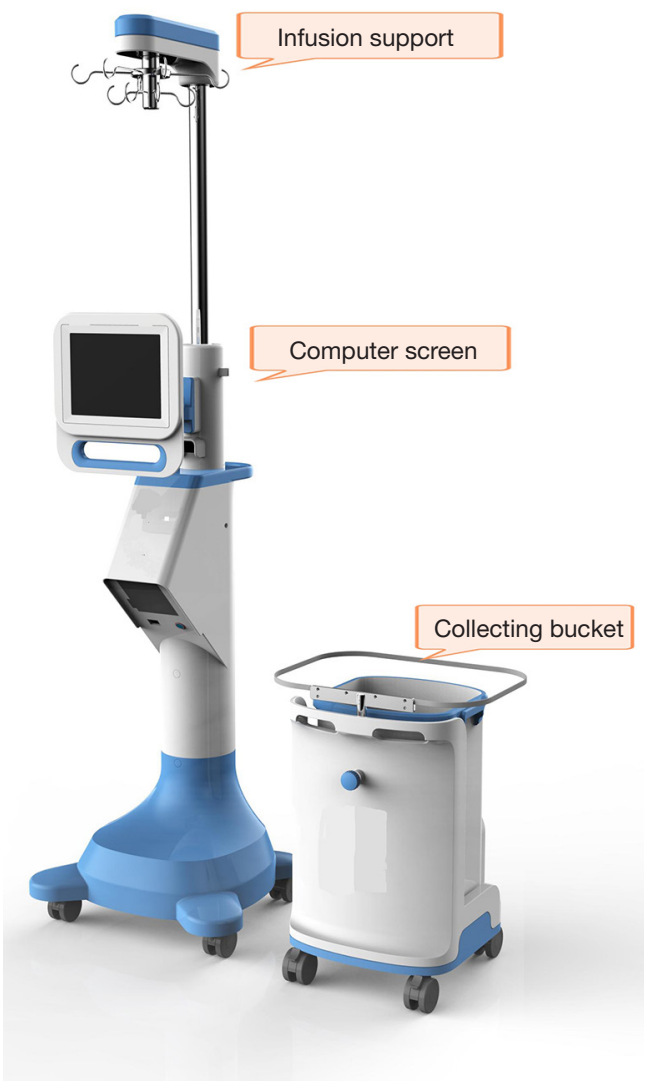

Figure 1 The first generation of prototype of endoscopic surgical monitoring system.

nervous systems during endoscopic surgery (1). Hemorrhage is one of the most important causes of morbidity during TURP. Because the blood is mixed with the irrigating fluid, the estimation of hemorrhage is more difficult than other operations. Knowledge of the total blood loss of the patient would allow haemorrhage to be managed more rationally.

At present, one of the difficulties in the management of patients undergoing endoscopic surgery is the lack of a practical and optimal method to detect fluid absorption and haemorrhage during the operation (2). This lack of information may result in an increased potential for the development of complications such as the TURS and shock. We therefore developed an intelligent monitoring system for the accurate and noninvasive measurement of fluid absorption and haemorrhage during urological endoscopic surgery and evaluated its validity. We present the following article in accordance with the STROBE reporting checklist (available at http://dx.doi.org/10.21037/tau-19-780).

\section{Methods}

\section{Design of endoscopic surgical monitoring system}

We designed this endoscopic surgical monitoring system based on the method of volumetric fluid balance. Volumetric fluid balance method measures the difference between the volume of used irrigating fluid and the volume of collected irrigating fluid, with a correction for blood loss and urine output during the urological endoscopic surgery. The formula used to calculate the absorption of irrigating fluid is: Absorbed fluid $=$ (fluid input + estimated urine output + estimated blood loss) - fluid output.

\section{Measurement of the inflows and outflows of irrigating fluid}

In our present monitoring system, weight was chosen as the appropriate parameter to observe the change of irrigating fluid in the closed system. We used strain gauge transducers to monitor fluid balance by measuring the weight change of irrigating fluid. This endoscopic surgical monitoring system consisted of two strain gauge transducers. One transducer was mounted on a specially designed infusion support for measuring the inflow of irrigating fluid, and another transducer was installed on the bottom of a specially designed collecting bucket for measuring the outflow of irrigating fluid.

The output from the transducers was passed via balancing circuitry and the analog signals were transformed by a CS1180 AD conversion chip. A serial link was used to transfer the above information to a computer (Toshiba) and a computer program and software was used to acquire and process the data. The volumes of inflow and outflow of irrigating fluid were calculated by the predetermined computer program based on the weight and density of the irrigating fluid. Then, the volumes of inflow and outflow of irrigating fluid were displayed on the computer screen (Figure 1). This equipment has been inspected and approved by Chinese Food and Drug Administration for manufacture (approved number: 20162210011) for clinical use.

\section{Estimation of the urine output}

The urine output produced per unit time after infusing different intravenous fluids was measured in a clinical study which included 100 inpatients. The results showed that after infusion of corresponding fluid, the fluctuating 

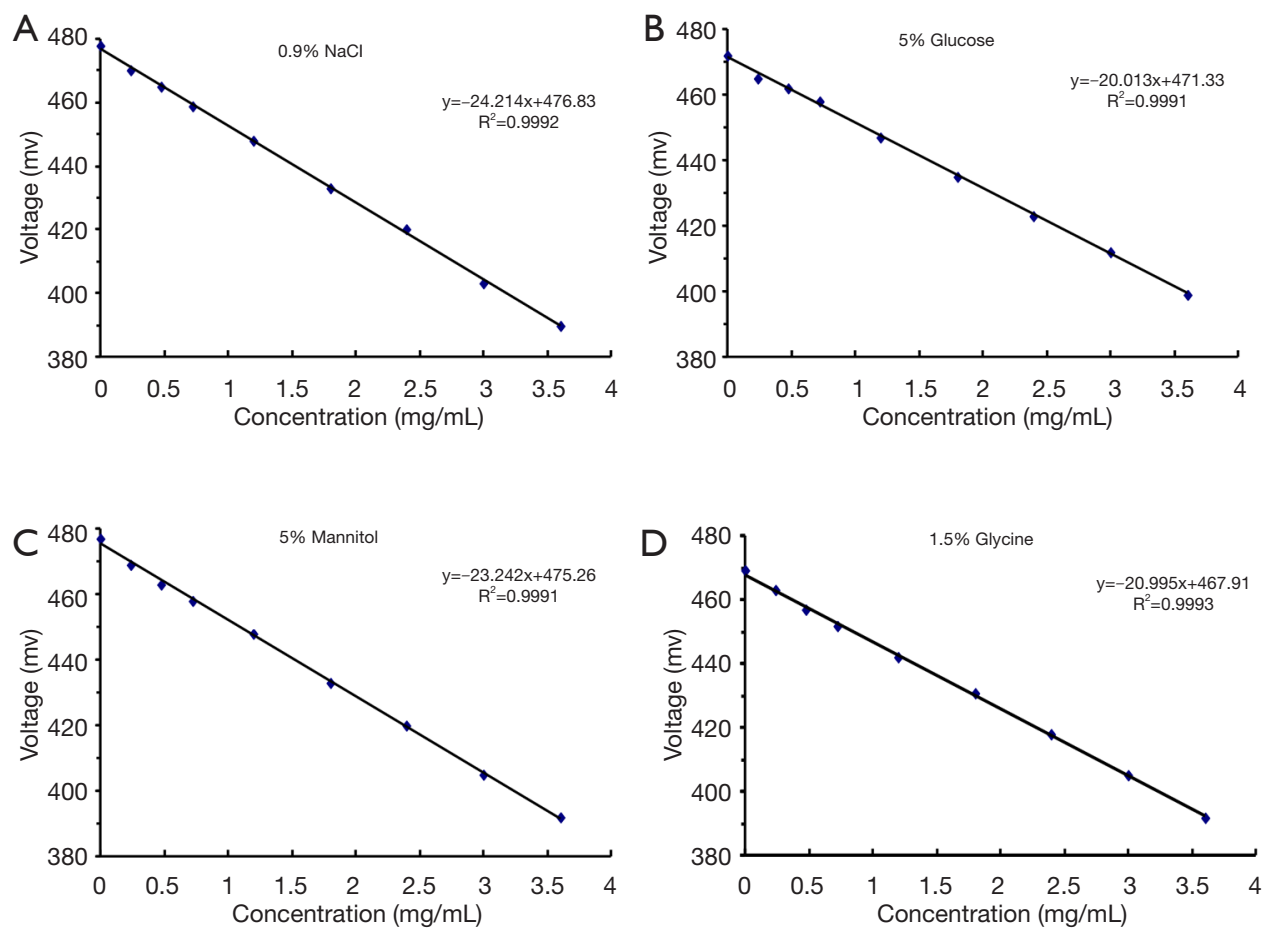

Figure 2 The influence of different irrigating solutions on the determination of the hemoglobin concentration. (A) The standard curve of hemoglobin when $0.9 \% \mathrm{NaCl}$ was used as irrigating solution; (B) the standard curve of hemoglobin when $5 \%$ glucose was used as irrigating solution; (C) the standard curve of hemoglobin when 5\% mannitol was used as irrigating solution; (D) the standard curve of hemoglobin when $1.5 \%$ glycine was used as irrigating solution.

range of urine output produced per unit time was relatively small. Therefore, the means of urine output produced per minute after infusing different fluids can be viewed as known parameters and input into the computer software for determination of irrigating fluid absorption.

\section{Determination of the blood loss}

The blood loss during the endoscopic surgery was calculated by measuring the blood hemoglobin concentration of patient prior to the operation $\left(\mathrm{Hb}_{\text {blood }}\right)$ and the hemoglobin concentration in the irrigating fluid collected in the collecting bucket $\left(\mathrm{Hb}_{\text {fluid }}\right)$ and then using the following formula:

Blood loss $=\left[\mathrm{Hb}_{\text {fluid }} / \mathrm{Hb}_{\text {blood }}\right]$ Collected irrigating fluid volume.

The volume of collected irrigating fluid could be calculated and obtained by above technique and procedure. To detect the hemoglobin concentration in the collected irrigating fluid we employed the photoelectric sensor. The photoelectric sensor was installed on the bottom of the collecting bucket. We established four standard curves of hemoglobin based on different irrigating solutions during endoscopic surgery and have input corresponding parameters into the computer software to calculate bleeding (Figure 2). Different amounts of blood dispersed in the irrigating fluid in the collecting bucket results in the change of the solution transmissivity. The change of optical signals was detected by the photoelectric sensor and then transformed to the electrical signals (voltage). The hemoglobin concentration in the collected irrigating fluid could be calculated by the predetermined computer program according to the irrigating solution used and corresponding hemoglobin standard curves. Then, the volume of blood lost during endoscopic surgery could be calculated by computer program using the above-mentioned formula.

\section{Estimation of the accuracy of strain gange transducer and photoelectric sensor}

Firstly, the accuracy of strain gauge transducer was tested. 
Different volumes $(50-8,000 \mathrm{~mL})$ of four irrigating solutions $(0.9 \% \mathrm{NaCl}, 5 \%$ glucose, $5 \%$ mannitol and $1.5 \%$ glycine) were hung on the infusion support or added to the collection bucket. The values of irrigating solutions volume displayed on the computer screen were recorded. The accuracy of strain gauge transducer was then assessed. Secondly, we tested the accuracy of photoelectric sensor. Known amounts (2-500 mL) of bank blood (Hb $120 \mathrm{~g} / \mathrm{L})$ were run into collection bucket containing known amounts $(2,000,4,000$ and $8,000 \mathrm{~mL})$ of four irrigating fluids. The solutions were stirred by the stirrer and the volumes of blood added to the bucket were displayed on the computer screen. The values were then recorded and the accuracy of photoelectric sensor was assessed. Each test was repeated six times.

\section{Estimation of the validity of this endoscopic surgical monitoring system in simulated absorption and bleeding experiment under laboratory environment}

In this test, $0.9 \% \mathrm{NaCl}, 5 \%$ glucose, $5 \%$ mannitol and $1.5 \%$ glycine were used as the irrigating solution and an irrigating fluid bag containing 3,000 $\mathrm{mL}$ of corresponding irrigating solution was hung on the specially designed infusion support. The fluid outflowed from the irrigating fluid bag through the outlet pipe and flowed into the collection bucket. The suction of known amounts (50$500 \mathrm{~mL}$ ) of irrigating fluid using a 50-mL syringe connected to the outlet pipe by a three-way cock simulated the fluid absorption during endoscopic surgery. Furthermore, the addition of known amounts $(30-240 \mathrm{~mL})$ of bank blood into the collection bucket simulated the hemorrhage during endoscopic surgery. Each test was repeated six times.

\section{Estimation of the validity of this endoscopic surgical monitoring system in clinical study}

This study was approved by the Ethics Committee of the Second Hospital of Lanzhou University (No. 2014-025; Date: March 4th, 2014). All patients provided a written informed consent. 200 patients with BPH undergoing TURP were recruited to assess the validity of our endoscopic surgical monitoring system for the monitoring of blood loss and fluid absorption. The age of the patients ranged from 57 to 82 years old with a mean of 71 years old. Spinal anaesthesia was used and resections were conducted using monopolar or bipolar systems by senior surgeons.
The monitoring of the patients consisted of systolic arterial pressure recordings with a sphygmomanometer (SAP), electrocardiography, perioperative complications, blood loss and irrigant fluid absorption by our endoscopic surgical monitoring system. Blood ion contents, plasma osmolarity and blood counts were determined before and within 10 min after TURP. All resected prostatic tissue weight, total operative time and any complications were recorded.

\section{Statistics}

Results were presented as the mean and standard deviation (SD). When there was a skewed distribution, the results were given as the median and the range.

\section{Results}

\section{The influence of different irrigating solutions on the determination of the hemoglobin concentration}

In order to evaluate the influence of different irrigating solutions on the determination of the hemoglobin concentration, we established four standard curves of hemoglobin using four different irrigating solutions. Eight hemoglobin standard concentrations were prepared by serial dilutions in four different irrigating solutions at concentrations of $0.24-3.6 \mathrm{mg} / \mathrm{mL}$ and ran in triplicate from beginning to the end of each batch. Linear regression analysis was used to construct standard curves by plotting the voltage values versus the respective hemoglobin concentrations (Figure 2). The regression equations from the standard curves were used to back calculate the hemoglobin concentration in the collected irrigating fluid. Figure 2 showed good linearity $\left(r^{2} \geq 0.9991\right)$ between voltage values and hemoglobin concentrations over the concentration range from 0.24 to $3.6 \mathrm{mg} / \mathrm{mL}$.

\section{The influence of infusing intravenously with different fluids on the urine output}

Our results showed that after infusion of corresponding fluid, the fluctuating range of urine output produced per unit time was relatively small and the means of urine output produced per minute can be viewed as known parameters (Table S1). The mean urine output was $1.99,1.87$ and $2.35 \mathrm{~mL}$ per minute after infusion of Ringer lactate, $0.9 \%$ $\mathrm{NaCl}$ and $5 \%$ glucose, respectively. 
Table 1 The accuracy of strain gauge transducer and photoelectric sensor

\begin{tabular}{|c|c|c|c|c|}
\hline Parameter & \multicolumn{4}{|c|}{ Irrigating solutions } \\
\hline \multicolumn{5}{|l|}{ Strain gauge transducer } \\
\hline Absolute error (range) & $0.30-2.85$ & $0.22-2.78$ & $0.32-2.25$ & $0.43-2.87$ \\
\hline Relative error \% (range) & $0.01-0.87$ & $0.01-1.00$ & $0.01-0.83$ & $0.02-0.95$ \\
\hline \multicolumn{5}{|l|}{ Photoelectric sensor } \\
\hline Absolute error (range) & $0.02-1.30$ & $0.02-1.68$ & $0.02-1.28$ & $0.02-1.62$ \\
\hline Relative error \% (range) & $0.08-1.67$ & $0.07-1.50$ & $0.10-1.33$ & $0.05-1.15$ \\
\hline Coefficient of variation \% (range) & $0.43-3.96$ & $0.46-3.99$ & $0.98-3.96$ & $1.09-3.92$ \\
\hline
\end{tabular}

\section{The accuracy of strain gauge transducer to measure irrigating fluid volume}

Our results showed high accuracy of strain gauge transducer for irrigating fluid volume detection (Table 1). When four different irrigating solutions were used, the relative errors of strain gauge transducer were between $0.01 \%$ and $1.00 \%$ and the coefficient of variation in serial analyses ranged from $0.07 \%$ to $3.90 \%$.

\section{The accuracy of photoelectric sensor for blood loss detection}

Our data indicated high accuracy of photoelectric sensor for measuring blood loss (Table 1). When four different irrigating solutions were used, the relative errors of photoelectric sensor were between $0.05 \%$ and $1.67 \%$ and the coefficient of variation in serial analyses ranged from $0.43 \%$ to $3.99 \%$.

\section{Estimation of the validity of this system in simulated blood loss and fluid absorption experiment}

Tables 2,3 showed the results obtained from the simulated fluid absorption and blood loss experiment and illustrated the validity of the monitoring system. The relative errors for fluid absorption detection were between $0.07 \%$ and $1.00 \%$ and the coefficient of variation in serial analyses ranged from $0.78 \%$ to $3.86 \%$. Furthermore, the relative errors for blood loss detection were between $0.06 \%$ and $1.33 \%$ and the coefficient of variation in serial analyses ranged from $0.86 \%$ to $3.94 \%$. This system proved stable and accurate for clinical requirement.

\section{Estimation of the validity of this system in clinical study}

As seen in Table 4, the mean operating time of TURP was 61 minutes (25-110 minutes). The mean resected weight of prostate was $22 \mathrm{~g}(8-36 \mathrm{~g})$. The mean volume of systemic irrigation fluid absorption during TURP was $644 \mathrm{~mL}(55-1,290 \mathrm{~mL})$. The mean volume of blood lost was $238 \mathrm{~mL}(29-430 \mathrm{~mL})$. There was no intraoperative and postoperative complications noted. No patient showed clinical signs of fluid absorption and no operation had to be curtailed or ended prematurely because of the absorption. Neither $\mathrm{Na}^{+}$concentrations nor plasma osmolarity showed any significant changes in all 200 patients. Our monitoring system was safe for patients and had no adverse effects on operations.

\section{Discussion}

Monitoring and detecting the absorption of irrigating fluid and haemorrhage during urological endoscopic operations is important to reduce the complications and to alert the surgeon to take the appropriate steps and corresponding treatments. The absorption of irrigating fluid and haemorrhage are difficult to monitor and are only estimated based on surgeon's clinical skill and experience. Various methods of estimating irrigating fluid absorption have been proposed. These methods include weighing the patient before and after the operation (3), measuring serum sodium levels $(4,5)$, estimating 'lost' irrigating fluid (6), monitoring central venous (7) or intravesical pressures (8), measuring irrigating fluid solute $(9,10)$ or marker substances levels $(11,12)$, and monitoring breath ethanol levels 
Table 2 Estimation of the validity of this system in simulated fluid absorption experiment

\begin{tabular}{|c|c|c|c|c|}
\hline Parameter & \multicolumn{4}{|c|}{ The volumes of simulated fluid absorption } \\
\hline \multicolumn{5}{|l|}{$0.9 \% \mathrm{NaCl}$} \\
\hline Mean \pm SD & $49.92 \pm 1.85$ & $99.53 \pm 3.10$ & $200.83 \pm 3.87$ & $500.92 \pm 4.85$ \\
\hline Absolute error & 0.08 & 0.47 & 0.83 & 0.92 \\
\hline Coefficient of variation, \% & 3.70 & 3.12 & 1.93 & 0.97 \\
\hline \multicolumn{5}{|l|}{$5 \%$ glucose } \\
\hline Mean \pm SD & $49.62 \pm 1.92$ & $101.00 \pm 2.27$ & $200.87 \pm 4.98$ & $500.88 \pm 5.52$ \\
\hline Absolute error & 0.38 & 1.00 & 0.87 & 0.88 \\
\hline \multicolumn{5}{|l|}{$5 \%$ mannitol } \\
\hline Mean \pm SD & $49.90 \pm 1.05$ & $100.98 \pm 2.83$ & $201.75 \pm 3.04$ & $498.83 \pm 5.36$ \\
\hline Absolute error & 0.10 & 0.98 & 1.75 & 1.17 \\
\hline Relative error, \% & 0.20 & 0.98 & 0.88 & 0.23 \\
\hline Coefficient of variation, \% & 2.11 & 2.80 & 1.51 & 1.07 \\
\hline \multicolumn{5}{|l|}{$1.5 \%$ glycine } \\
\hline Mean \pm SD & $50.03 \pm 1.91$ & $100.43 \pm 2.67$ & $200.85 \pm 2.83$ & $500.83 \pm 3.90$ \\
\hline Absolute error & 0.03 & 0.43 & 0.85 & 0.83 \\
\hline
\end{tabular}

(13-17). Most of the traditional methods are complicated and cumbersome for use in everyday clinical practice. In these methods there are some deficiency such as inaccurate, difficult to interpret, involving the invasive procedures or radioisotopes, and the potential for complicating or delaying the surgery. The previous techniques reflect the consequences arising from massive fluid absorption rather than giving early warning, and cannot real-time quantified. Measurement of the levels of irrigating fluid solute are complicated and time consuming, precluding this method as a rapid 'bedside' assay. Although variations in serum sodium levels are commonly thought to reflect the fluid absorption, homeostatic mechanisms render them inaccurate after the first few minutes of absorption (5). Ethanol monitoring method has been used in some clinical practices and has attracted a lot of interest. However, it only gives the warning of intravascular absorption, and not giving early warning of extracapsular leaks or changes in total fluid balance. Additionally, it relies on a relatively simple formula to correct for the effects of ethanol metabolism, diffusion and excretion, making quantification of the total fluid absorption questionable (18). All these problems have addressed the urgent need for a non-invasive, accurate and reliable method and device to monitor the absorption of irrigating fluid and haemorrhage at an early stage and real time to reduce further fluid overload and complications.

To meet urological endoscopic practice needs, the present endoscopic surgical monitoring system was developed. Our monitoring system measures total fluid balance, and hence both intravascular and extra-peritoneal fluid absorption. We also take into account the effects of blood loss and urine output on total fluid balance. Compared with other methods described in the literatures, the present monitoring system is a non-invasive, accurate, 
Table 3 Estimation of the validity of this system in simulated blood loss experiment

\begin{tabular}{|c|c|c|c|c|}
\hline Parameter & \multicolumn{4}{|c|}{ The volumes of simulated blood loss $(\mathrm{mL})$} \\
\hline \multicolumn{5}{|l|}{$0.9 \% \mathrm{NaCl}$} \\
\hline Mean \pm SD & $30.40 \pm 0.96$ & $60.45 \pm 1.19$ & $121.08 \pm 2.55$ & $241.97 \pm 4.45$ \\
\hline Absolute error & 0.40 & 0.45 & 1.08 & 1.97 \\
\hline Coefficient of variation, \% & 3.17 & 1.98 & 2.10 & 1.84 \\
\hline \multicolumn{5}{|l|}{$5 \%$ glucose } \\
\hline Mean \pm SD & $30.32 \pm 1.07$ & $60.70 \pm 1.44$ & $120.92 \pm 2.46$ & $239.15 \pm 3.18$ \\
\hline Absolute error & 0.32 & 0.70 & 0.92 & 0.85 \\
\hline \multicolumn{5}{|l|}{$5 \%$ mannitol } \\
\hline Mean \pm SD & $30.07 \pm 1.10$ & $59.35 \pm 1.80$ & $120.58 \pm 2.12$ & $239.48 \pm 2.07$ \\
\hline Absolute error & 0.07 & 0.65 & 0.58 & 0.52 \\
\hline Relative error, \% & 0.22 & 1.08 & 0.49 & 0.22 \\
\hline Coefficient of variation, $\%$ & 3.65 & 3.03 & 1.76 & 0.86 \\
\hline \multicolumn{5}{|l|}{$1.5 \%$ glycine } \\
\hline Mean \pm SD & $29.98 \pm 1.18$ & $60.27 \pm 1.95$ & $120.93 \pm 2.24$ & $239.72 \pm 2.08$ \\
\hline Absolute error & 0.02 & 0.27 & 0.93 & 0.28 \\
\hline
\end{tabular}

Table 4 Estimation of the validity of this system in clinical study

\begin{tabular}{lccr}
\hline Variables & Mean & SD & Range \\
\hline Age (years) & 71 & 6 & $57-82$ \\
Operating time (min) & 61 & 17 & $25-110$ \\
Weight of resected prostate $(\mathrm{g})$ & 22 & 6 & $8-36$ \\
Fluid absorption $(\mathrm{mL})$ & 644 & 270 & $55-1290$ \\
Blood lost $(\mathrm{mL})$ & 238 & 98 & $29-430$ \\
\hline
\end{tabular}

rapid and real-time analysis, and the amounts of fluid absorption and haemorrhage are directly displayed on the computer screen. We think that this monitoring system has significant advantages and will influence the management of patients undergoing endoscopic surgery by giving early warning of significant fluid absorption and haemorrhage.
The analytical performance of our monitoring system has been validated with respect to the linearity and accuracy, presenting adequate performance characteristics in simulated experiment of fluid absorption and blood lost, which meets clinical requirement and use. In addition, a clinical study was performed to estimate the performance 
and validity of this monitoring system. The system was proved stable and accurate both in laboratory environment and in clinical study. This equipment of endoscopic surgical monitoring system can be used in both urological and hysteroscope endoscopic operation to monitor fluid absorption and haemorrhage to prevent TURS or shock caused by bleeding.

\section{Conclusions}

This endoscopic surgical monitoring system was proved to have the advantages of high accuracy and reliability. This monitoring system provides a valid and non-invasive method of continuously monitoring fluid absorption and blood loss in patients undergoing endoscopic surgery. The usage of this monitoring system in the clinic will significantly decrease the complications and make the endoscopic surgery safer for the patient and easier for the surgeon. So, we conclude that the endoscopic surgical monitoring system will have a good prospect for clinical application.

\section{Acknowledgments}

Funding: This work was supported by Gansu Aokai Medical Equipment Co. Ltd. This study was supported by the Fundamental Research Funds for the Central Universities (No: lzujbky-2018-k06), Special Fund Project for Guiding the Development of Science and Technology Innovation of Gansu Province (No: 2017ZX-01), Natural Science Foundation of Gansu Province (No: 1606RJZA124), Cuiying Scientific and Technological Innovation Program of Lanzhou University Second Hospital (No: CY2017MS10), Doctoral Research Fund of Lanzhou University Second Hospital (No: ynbskyji2015-1-22) and Scientific Research Project of Health Industry of Gansu Province (No: GSWSKY2016-18).

\section{Footnote}

Reporting Checklist: The authors have completed the STROBE reporting checklist. Available at http://dx. doi. org/10. 21037/tau-19-780

Conflict of Interest: All authors have completed the ICMJE uniform disclosure form (available at http://dx. doi. org/10.21037/tau-19-780). The authors have no conflicts of interest to declare.
Ethical Statement: The authors are accountable for all aspects of the work in ensuring that questions related to the accuracy or integrity of any part of the work are appropriately investigated and resolved.

Open Access Statement: This is an Open Access article distributed in accordance with the Creative Commons Attribution-NonCommercial-NoDerivs 4.0 International License (CC BY-NC-ND 4.0), which permits the noncommercial replication and distribution of the article with the strict proviso that no changes or edits are made and the original work is properly cited (including links to both the formal publication through the relevant DOI and the license). See: https://creativecommons.org/licenses/by-nc-nd/4.0/.

\section{References}

1. Hahn RG. The transurethral resection syndrome. Acta Anaesthesiol Scand 1991;35:557-67.

2. Coppinger SW, Lewis CA, Milroy EJ. A method of measuring fluid balance during transurethral resection of the prostate. Br J Urol 1995;76:66-72.

3. Hagstrom RS. Studies on fluid absorption during transurethral resection. J Urol 1955;73:852-9.

4. Watkins-Pitchford JM, Payne SR, Rennie CD, et al. Hyponatraemia during transurethral resection-its practical prevention. Br J Urol 1984;56:676-8.

5. Hahn RG. Relations between irrigant absorption rate and hyponatraemia during transurethral resection of the prostate. Acta Anaesthesiol Scand 1988;32:53-60.

6. Hahn R, Berlin T, lewenhaupt A. Irrigating fluid absorption and blood loss during transurethral resection of the prostate studied by a regular interval monitoring (RIM) method. Scand J Urol Nephrol 1988;22:23-30.

7. Hahn R, Berlin T, Lewenhaupt A. Rapid massive irrigating fluid absorption during transurethral resection of the prostate. Acta Chir Scand Suppl 1986;530:63-5.

8. Reuter HJ, Jones LW. Physiologic low pressure irrigation for transurethral resection: suprapubic drainage. J Urol 1974;111:210-2.

9. Norlén H, Allgen LG, Vinnars E, et al. Glycine solution as an irrigating solution during transurethral prostatic resection. Scand J Urol Nephrol 1986;20:19-26.

10. Norlén H, Allgen LG, Wicksel B. Sorbitol concentrations in plasma in connection with transurethral resection of the prostate using sorbitol solution as an irrigating fluid. Scand J Urol Nephrol 1986;20:9-17.

11. Landsteiner EK. Hemoglobinemia accompanying 
transurethral resection of the prostate. $\mathrm{N}$ Engl J Med 1947;237:310-2.

12. Oester A, Madsen PO. Determination of absorption of irrigating fluid during transurethral resection of the prostate by means of radioisotopes. J Urol 1969;102:714-9.

13. Hahn RG. Calculation of irrigant absorption by measurement of breath alcohol level during transurethral resection of the prostate. Br J Urol 1991;68:390-3.

14. Hultén JO, Hahn RG. Monitoring irrigating fluid absorption during transurethral resection of the prostate (TURP); a comparison between 1 and $2 \%$ ethanol as a

Cite this article as: Zhang Y, Fan N, Zhang L, Hu X, Wang L, Wang H, Kaushik D, Rodriguez R, Wang Z. Novel strategy to monitor fluid absorption and blood loss during urological endoscopic surgery. Transl Androl Urol 2020;9(3):1192-1200. doi:10.21037/tau-19-780 tracer. Scand J Urol Nephrol 1989;23:103-8.

15. Hahn RG. Early detection of the TUR syndrome by marking the irrigating fluid with $1 \%$ ethanol. Acta Anaesthesiol Scand 1989;33:146-51.

16. Hultén J, Sarma VJ, Hjertberg H, et al. Monitoring of irrigating fluid absorption during transurethral prostatectomy. Anaesthesia 1991;46:349-53.

17. Hahn RG. Prevention of TUR syndrome by detection of trace ethanol in expired breath. Anaesthesia 1990;45:577-81.

18. Editorial. Monitoring TURP. Lancet 1991;338:606-7. 
Supplementary

Table S1 The influence of infusing intravenously with different fluids on the urine output

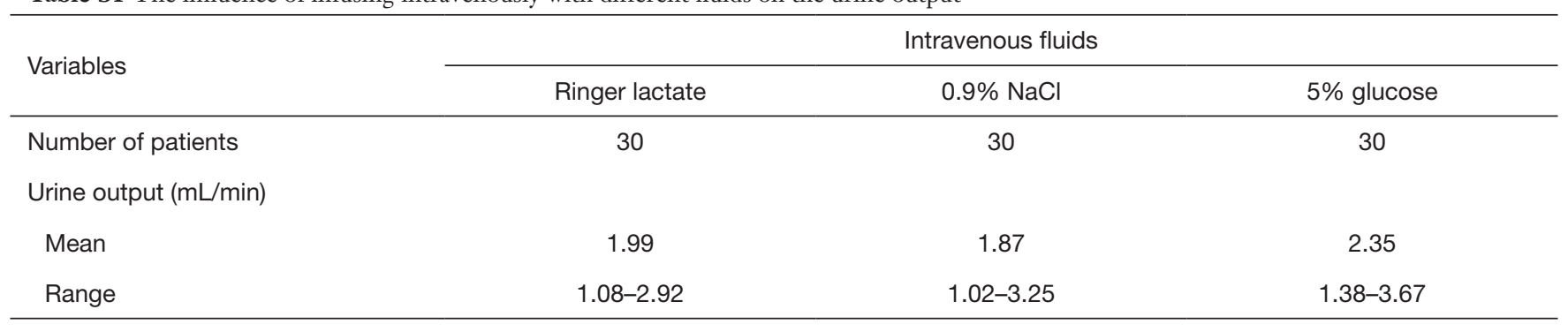

